\title{
REVIEW OF MAGNETIC CARRIER TECHNOLOGIES FOR METAL ION REMOVAL
}

\author{
J. BROOMBERG, S. GÉLINAS, J.A. FINCH* and Z. XU \\ Department of Mining and Metallurgical Engineering, McGill University, \\ Wong Building, 3610 University, Montréal, H3A 2B2, Canada
}

(Received 3 June 1998; Accepted 2 September 1998)

\begin{abstract}
Magnetic carriers are magnetic materials designed to bind selectively on some non -magnetic materials to make them separable using magnetic separation. It allows magnetic separation, a fast, efficient, high capacity and well-developed industrial technology, to be applied to the separation of materials that are otherwise non-magnetic. One application is in metal ion recovery from dilute effluents. Magnetic carrier technologies offer some advantages over other more conventional metal ion separation techniques such as ion exchange, carbon adsorption, and precipitation. Various magnetic carrier technologies have been developed using different magnetic materials (for example, micro-sized magnetite of magnetic oils) and controlling the attachment of the carrier to the target species through specific binding mechanisms (for example, electrostatic adsorption or chemical affinity). A full-scale industrial water treatment application is illustrated in the case of the Sirofloc process. The review summarizes the efforts over the last twenty years to develop carriers with high loading capacity and selectivity. General principles for the design of magnetic carriers are summarized.
\end{abstract}

Keywords: Magnetic carrier; Metal ion removal; Magnetic separation; Selective binding; Magnetic supports; Treatment of dilute effluents

\section{INTRODUCTION}

Magnetic carrier technology originated in the early 1940s, when magnetite was used to remove organic impurities from wastewater streams using electrostatic adsorption [1]. Since the early 1970s, many efforts have been made to develop magnetic carrier technologies in fields as

\footnotetext{
* Corresponding author.
} 
diverse as biological cell separation, drug delivery, effluent treatment, mineral separation, and food processing.

Magnetic carrier technology, or more generically 'magnetic support' technology was introduced to extend magnetic separation to materials that are not naturally magnetic [2]. Magnetic supports are materials aimed at selectively enhancing the magnetic properties of the nonmagnetic material (the target) that needs to be separated. They can be particles (usually called 'carriers') or liquids such as oils (hence the wider term 'supports'). Magnetic support materials should fulfill two functions [2]: first, provide highly selective attachment to the target species through appropriate surface properties; second, confer magnetic properties to those targets to be separated.

Magnetic supports are of particular interest for the separation of fine particles, colloids, and organics, which are slow and difficult to separate by classical methods. In the case of the food industry, Dixon showed that conventional methods were not appropriate to separate impurities of low molecular weight from a stream containing both larger product molecules and suspended solids [3]. There were two requirements: (i) specific adsorption of the impurity, and (ii) separation of the loaded adsorbent from the aqueous suspension. Dixon showed that magnetic polymer beads were suitable for such a separation [3]. Another advantage of magnetic support technology is that it can remove impurities down to very low concentrations; an increase in the amount of magnetic adsorbent will increase the target uptake, and removal to trace levels is possible [4].

Our main interest is the possible application in the selective recovery of metal ions from effluents generated in the metallurgical industry. We will start the review with general principles, touch on a variety of applications, then return to assess the potential for metal ion recovery.

\section{GENERAL PRINCIPLES}

\section{Separation Using Magnetic Carriers}

The action of magnetic support particles is to enhance the magnetic properties of a non-magnetic material so that its magnetization under a given magnetic flux approaches that of the same volume of a typical paramagnetic material (i.e., sufficient to make it separable with an 
TABLE I Variation of magnetization $M$ with flux density $B$ for paramagnetic materials, and magnetite content of non-magnetic particle for equivalent magnetization (source: Ref. [5])

\begin{tabular}{lccc}
\hline $\begin{array}{l}\text { Volume susceptibility of } \\
\text { paramagnetic mineral, } \\
\chi \text { (SI units) }\end{array}$ & $\begin{array}{c}\text { Magnetic flux } \\
\text { density, } B(\mathrm{~T})\end{array}$ & $\begin{array}{c}\text { Magnetization } M \\
\left(\mathrm{~A} \mathrm{~m}^{-1}\right)\end{array}$ & $\begin{array}{c}\text { Magnetite content of } \\
\text { non-magnetic particles } \\
\text { to give equal magnetization } \\
\text { (volume \%) }\end{array}$ \\
\hline $5 \times 10^{-3}$ & 0.2 & $8 \times 10^{2}$ & 0.17 \\
& 1 & $4 \times 10^{3}$ & 0.83 \\
$10^{-3}$ & 2 & $8 \times 10^{3}$ & 1.66 \\
& 0.2 & $1.6 \times 10^{2}$ & 0.03 \\
& 1 & $8 \times 10^{2}$ & 0.17 \\
& 2 & $1.6 \times 10^{3}$ & 0.33 \\
\hline
\end{tabular}

industrial magnetic separator). To achieve that, only a small amount of strongly magnetic material is necessary. Ferro- or ferrimagnetic materials such as ferrosilicon and magnetite have susceptibilities orders of magnitude greater than typical paramagnetic materials. A volume fraction of magnetic support material in the range $0.1-1 \%$ is usually enough to achieve suitable magnetization of a non-magnetic material. Table I (adapted from [5]) shows the magnetization of different paramagnetic materials under given flux densities, and the corresponding amounts of magnetite to be added to a non-magnetic material for equivalent magnetization.

Figure 1 illustrates the principle of magnetic carrier separation. Magnetic supports are added to a mixture containing target species. The magnetic supports selectively bind to the target, and magnetic separation allows the separation of the targets from the undesired species. This method can be used either to recover valuable species, or to remove undesired ones from a stream.

\section{Magnetic Carriers and Magnetic Tags}

Moffat et al. classified magnetic support materials in two groups, magnetic carriers and magnetic tags [2]. Magnetic carriers are usually 10-1000 times larger than the target species. The principle is to vary the surface characteristics (of the carrier), to achieve selective recovery of colloidal and macromolecular (or ionic) species by attaching them to the carrier surface, or entrapping them within a magnetic carrier particle [2]. Figure 2 shows the case where the target coats the surface of the magnetic carrier (i), and the case where the targets are entrapped within a porous 


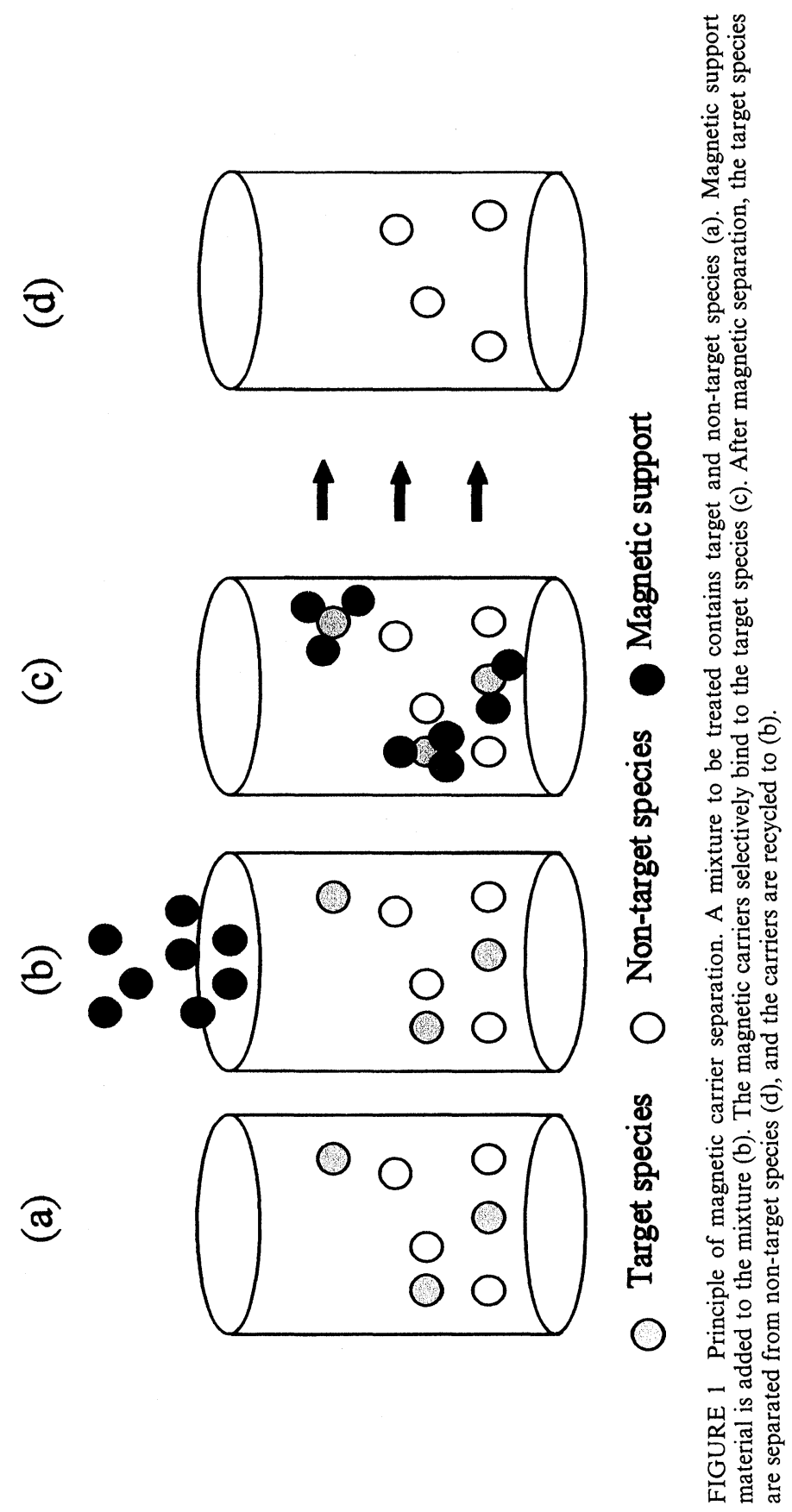




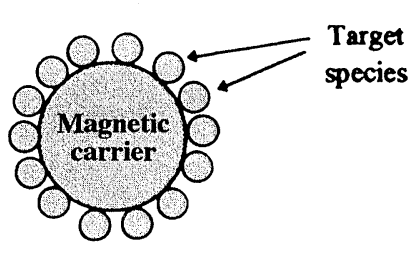

(i) Magnetic carrier coated with non-magnetic targets.

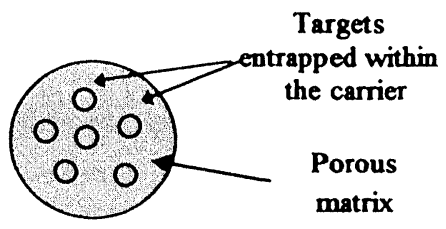

(ii) Targets entrapped within a porous magnetic carrier

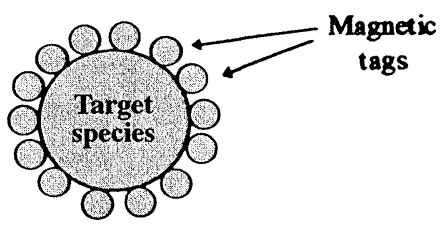

(iii) Target coated with magnetic tags.

FIGURE 2 Schematic representation of magnetic carrier ((i) and (ii)), and magnetic tagging (iii) technologies (adapted from [2]).

magnetic carrier (ii). A related technology is magnetic tagging. The tags are usually smaller than the particles to be separated. Tags can be either ions (e.g., $\mathrm{Y}^{3+}$ ) or fine magnetic particles (e.g., $\mathrm{Fe}_{3} \mathrm{O}_{4}$ ) that coat or cluster around non-magnetic species in order to allow them to be manipulated using external magnetic fields [2]. The mechanism of tagging can be through very specific coupling mechanisms (e.g., an antibody-antigen interaction), or through electrostatic adsorption. Figure 2 (iii) is an illustration of the tagging mechanism.

\section{MAGNETIC CARRIER APPLICATIONS}

\section{Biological and Pharmaceutical Applications}

There is an abundant literature on biological and pharmaceutical applications of magnetic carriers. For a review, and for references, see Moffa et al. [2]. For now, only the principles of different methods will be outlined.

The key concept of biological cell separation is that of affinity separation [2]. Affinity separation refers to specific interaction between 
the magnetic carrier and the target. For instance, highly selective separations can be achieved by exploiting reversible complex formation between two or more interacting biological species. The principle is so-called key-lock. The magnetic carriers are made so that they contain a functional group (e.g., an antibody) that will react only with one specific target (e.g., an antigen). The tags developed in that way are sometimes called magnetic bio-affinity materials.

Another area of application is drug or reagent delivery [2]. By incorporating drugs in a magnetic microsphere, they can be delivered to a specific site in the body. After injection, a bipolar magnetic field is placed around the targeted area in the body and an appropriate magnetic field is applied to hold the drug in the capillaries against the flow of blood.

A magnetic carrier designed for medical and biological applications has been described by Ugelstad et al. [6]. They have prepared hydrophilic micrometer-sized particles consisting of polymer latex impregnated with approximately $20 \% \mathrm{w} / \mathrm{w}$ single domain maghemite. These composite particles were synthesized by the in situ oxidation of iron salts within the polymer latex and are commercially available as magnetic carriers.

\section{Effluent Processing and Metal Ion Removal}

\section{Bare Magnetic Carriers}

Some of the pioneering work on the use of magnetite for the removal of metal ions (and suspended solids) from a solution was performed by de Latour [7]. He studied the precipitation of $\mathrm{Al}(\mathrm{III}), \mathrm{Fe}(\mathrm{III})$, and $\mathrm{Cu}$ (II) and their co-precipitates after addition of magnetite seed. The main finding was the correlation between the zeta-potential of the different precipitated species and their removal. Maximum removal occurred around the point of zero charge of the precipitates. De Latour's work showed that in the case of magnetite, the main adsorption mechanism is electrostatic. That study also demonstrated that the way to alter adsorption on magnetite was to vary the $\mathrm{pH}$, to add coagulants, and to compress the double layer by increasing the electrolyte concentration.

Selective magnetic coating for mineral separation was studied by Parsonage using precipitated colloidal magnetite [8]. To distinguish, the magnetite in de Latour's work was used as a carrier, whereas in Parsonage's work it was used as a tag. Parsonage studied the stability of the magnetite colloid, demonstrating that stability was dependent on $\mathrm{pH}$ 
and on the addition of surfactants (oleate, and dodecylamine). The point of zero charge (pzc) of magnetite alone was found to be $\mathrm{pH}$ 6.5. The presence of the anionic oleate surfactant resulted in a shift in pzc to $\mathrm{pH} 4.5$. With the cationic amine the zeta-potential was positive over the $\mathrm{pH}$ range $3-11$. The stability of the magnetite colloid was well correlated with the pzc of the suspended particles.

The interest in controlling the surface charge of the colloid is twofold. First, a well-dispersed colloid is preferred to maximize the reactive surface area available. Second, controlling the surface charge of the colloid is necessary to control the selectivity of electrostatic adsorption on the target species. Parsonage demonstrated selective coating of magnetite on calcite but not on apatite at $\mathrm{pH} 11$, resulting in magnetic separation of the two minerals.

Work by Terashima et al. [9] on the removal of dissolved heavy metals by combination of chemical coagulation, magnetic seeding, and high gradient magnetic separation corroborated the results of both de Latour and Parsonage. They showed that in the case of dissolved heavy metals, magnetic agglomerates can be formed by coagulating precipitates with magnetic seeds through adjustment of the chemistry. They also found that the coupling (or binding) of the magnetic seeds with the targets was primarily due to surface charge (through electrostatic interactions), and the capture of particles in the mesh structure of precipitated $\mathrm{Fe}(\mathrm{OH})_{3}$.

To summarize, the main factor controlling the selectivity of magnetite attachment to target species appears to be electrostatic interaction. Selectivity is therefore mainly controlled by surface charge of particles and targets through the addition of appropriate $\mathrm{pH}$ modifiers and electrolytes. A secondary issue is controlling dispersion, or coagulation (to produce entrapment), which involves $\mathrm{pH}$ modifiers, electrolytes and surfactants.

\section{Gel Coated Magnetite}

The incentive to use gel-coated magnetite was to increase the carrier's specific surface area and hence to increase adsorption capacity. Commercial magnetite tends to have a low specific surface area, and is therefore not a very good adsorbent by itself, in comparison, say, to amorphous Fe oxide gels [4]. Ferrihydrite was chosen by Chen et al. because it was amorphous and had well-known characteristics. They 
report that surface binding site density was $1.33 \times 10^{-3} \mathrm{~mol} / \mathrm{g}$ for ferrihydrite as compared to only $2.0 \times 10^{-5} \mathrm{~mol} / \mathrm{g}$ for $2 \mu \mathrm{m}$-sized magnetite (that is, more than 50 times lower) [4].

Chen et al. studied the removal of $\mathrm{Cr}(\mathrm{VI})$ and $\mathrm{Zn}$ using a composite adsorbent prepared by precipitating ferrihydrite onto magnetite [4]. During the first cycle, the coated particles adsorbed twice as much metal as non-coated magnetite. This application was found to have two main drawbacks. First, a decline in adsorbent performance was observed, due to the accumulation of adsorbate on the solids (after 10 cycles, the adsorbent had lost $90 \%$ of its capacity). Second, the composite adsorbent was found to lose its coating during desorption.

A similar study was reported by Anderson et al. [10]. Ferric hydroxide gel was deposited on fine magnetic particles, and tested for the removal of color and turbidity from wastewater. The study pointed to the amphoteric behavior of ferric oxide, meaning that its surface can be either acidic (i.e., positive) or basic (i.e., negative) depending on the $\mathrm{pH}$. The surface species involved are:

$$
\begin{gathered}
\mathrm{Fe}-\mathrm{OH}+\mathrm{H}^{+} \Leftrightarrow \mathrm{FeOH}_{2}^{+} \\
\mathrm{Fe}-\mathrm{OH}+\mathrm{OH}^{-} \Leftrightarrow \mathrm{FeO}^{-}+\mathrm{H}_{2} \mathrm{O}
\end{gathered}
$$

In this work the pzc for ferric oxide was about $\mathrm{pH}$ 8. Negatively charged colloids were adsorbed at $\mathrm{pH}$ below 8 , and particles were regenerated at $\mathrm{pH}$ above 8 . The main drawback of this method, as in the previous, was the poor integrity (i.e., long term stability) of the gel coatings. Substantial gel loss occurred after each regeneration, and in some cases all the gel was gone after as few as 6 cycles. More information on the amphoteric nature of the ferric oxide surface, and adsorption phenomena on oxide surfaces can be found in the study by Benjamin et al. [11].

\section{Magnetic Polymer Resins}

Work on magnetic polymeric beads, also called magnetic resins, was initiated by Bolto et al. in Australia, in the Division of Chemical Technology of the CSIRO [12]. The initial idea was a continuous ion exchange process to overcome some problems of the conventional ion exchange process. In compact bed systems, the operation is not truly continuous, is relatively complex, and attrition of the resin can be significant. The use of 
conventional ion exchangers in a fluidized bed suffers from the low density difference between the resin and water phases, resulting in reduced contacting and stage efficiency. Magnetic ion exchangers were designed to increase sedimentation rate (by exploiting magnetic flocculation), without decreasing reactivity so that they could be used in continuous fluidized bed systems. Such ion exchangers are characterized by high reaction rates (as a result of small particle size, and large reactive surface area) as well as fast sedimentation [12].

Two principal types of magnetic resins (i.e., homogeneous and heterogeneous) have been developed. Homogeneous resins consist either of a magnetic material uniformly distributed within the cross-linked ionexchange resin, or of magnetic material and micro ion exchangers (e.g., activated carbon), uniformly distributed within an inert cross-linked polymer [13]. In this latter type, selectivity is controlled by allowing the permeability of the resin to vary by the nature and degree of cross-liking of the polymer backbone, in order to limit the size of the molecules able to penetrate the resin matrix [3]. Laboratory and pilot plant studies were carried out to test the use of these magnetic resins in the dealkilization of water, and showed the technical viability of such applications $[12,14]$. However, the regeneration of the resins was not easy, and if it required a strong acid or base, the magnetic oxide could degrade [3].

The second type of resins, heterogeneous, or whisker type resins, consist of active polymeric chains grafted onto a core of magnetic polymer of the former homogeneous type [13]. The claimed advantage of the heterogeneous type is that grafting of a precursor monomer followed by chemical modification enables a wider range of exchange resins to be produced [15]. For heterogeneous resins, the selectivity can be tailored by choosing the appropriate type of active polymer to be grafted on the surface. This capability to tailor the selectivity of the carrier by choosing the functional group of the graft is referred to as functionalization.

Anderson et al. [16] tested different types of homogeneous and heterogeneous magnetic resins for the removal of color and turbidity from wastewater, and found two main problems. First, the polymer grafted resins could become irreversibly fouled, and second the cost of the particles was prohibitive. Research on these kinds of magnetic resins was consequently discontinued.

More recently, Furusawa et al. [17] have prepared particles consisting of a micrometer-sized polystyrene latex core coated with a shell of 
ultrafine $(d<20 \mathrm{~nm})$ magnetic particles. Another study, from Butterworth et al. [18], reports on the synthesis of colloidal dispersions by polymerizing pyrrole in ultrafine silica-coated magnetite suspensions.

\section{Sirofloc $^{\mathrm{TM}}$ Process}

The same CSIRO research group tested the direct use of magnetite particles [19]. Magnetite particles were activated at $\mathrm{pH} 4-6$, resulting in protonated surfaces following a mechanism similar to that discussed in the section on bare magnetic iron oxide carriers (reaction (1)). Protonated surfaces provide good adsorption sites for negatively charged colloids or suspended solids. The study showed that alkali treated magnetite was an effective reusable coagulant-adsorbent. Adsorption was performed at $\mathrm{pH} 4-6$, and regeneration was achieved in a weak $(0.1 \mathrm{M}) \mathrm{NaOH}$ solution. It was also shown that for highly turbid and colored waters, an alternative preferable to adding more magnetite was to add small amounts of coagulant or flocculant. The effect of magnetite particle size, $\mathrm{pH}$, and stirring speed was investigated. Very poor coagulation was obtained for particles above $6 \mu \mathrm{m}$, due to their low specific surface area. For particles below $1 \mu \mathrm{m}$, on the other hand, settling rates were detrimentally slow. The operating size was consequently chosen in the range $1-5 \mu \mathrm{m}$. Removal was effective only below $\mathrm{pH} 5$, due to a more protonated surface, and to the compression of the double layer. Too low a stirring speed resulted in fewer particle-particle contacts and lower removal efficiency, while too high a rate of stirring resulted in excessive shear forces which disrupted agglomerates. Stirring speed of $160 \mathrm{rpm}$ was selected for the mixing stage. Regeneration was performed in $0.1 \mathrm{M}$ $\mathrm{NaOH}$, and 'no significant deterioration in the adsorption efficiency over prolonged reuse' was observed. This work from Kolarik [19] was the starting point for the development of a very successful process for wastewater treatment, the Sirofloc ${ }^{\mathrm{TM}}$ process. Process development, pilot plant studies, and full-scale applications will be presented in the section on process development and industrial applications.

Subsequent research on the Sirofloc ${ }^{\mathrm{TM}}$ process investigated the role of different polyelectrolytes in water clarification, which led to a better understanding of the process [20]. The proposed mechanism is the following. At pH 6, magnetite has a positive surface charge. Upon contact with water it rapidly adsorbs color in the form of soluble organic anions 
and some of the negatively charged turbidity particles. The loaded magnetite then has a negative surface charge. The addition of cationic polyelectrolytes causes the remaining negatively charged impurities to be bound to the loaded magnetite, with the polymer acting as a bridge. A more recent study showed that traces of cationic polymer can become attached to the negatively charged oxide under alkaline regeneration conditions [21]. It was concluded that an ideal polymeric agent would be one that is cationic under acidic condition and neutral or preferably anionic in alkali solution. Such polymers are called amphoteric polymers. A trade-off must be found between the anionic character of the polymer, which improves regeneration, and the cationic character, which allows for high removal efficiency.

\section{Surfactant Functionalized Magnetic Carriers}

Functionalization of magnetic carriers was mentioned in the section on the whisker-type heterogeneous resins created by Bolto et al. The goal was to graft active polymeric chains on a core magnetic resin in order to tailor an active functional group for adsorption of the target species. A similar idea can be applied using surfactants instead of polymers. Using sequential layering of amphiphilic molecules on the surface of magnetic particles, Hwang engineered a unilamellar magnetic liposome [22,23]. The inner layer amphiphile has a functional group with an affinity for the metal oxide surface, and the outer layer amphiphile is built on top of the inner one through hydrophobic association between hydrocarbon chains.

Another development in this direction was initiated by Liu and $\mathrm{Xu}$ $[24,25]$. They investigated the functionalization of nanosized maghemite $\left(\gamma-\mathrm{Fe}_{2} \mathrm{O}_{3}\right)$ particles by coating them with a monolayer of bolaamphiphile surfactants. A bolaamphiphile surfactant contains two different headgroups, one at each end, in this case with one group intended to bind to the magnetite particle and the other designed to attach to the target. The bolaamphiphile used was $\mathrm{HS}-\left(\mathrm{CH}_{2}\right)_{15}-\mathrm{COOH}$ (16-mercaptohexadecanoic acid). It was demonstrated that the surfactant is anchored to the magnetic particle by chemisorption via the carboxylic $(\mathrm{COOH})$ group, and that the adsorbed layer is dense and resistant to acid or base leaching [24]. Further tests showed that thio groups are reactive for adsorption of metal ions such as silver and copper [25]. 
It was also demonstrated that the loaded metal ion could be removed by acid stripping, but that the loading performance tended to decrease upon subsequent reuse [26]. More systematic work remains to be done to assess selectivity and the performance of such functionalized particles upon prolonged use.

\section{Silanation on Metal Oxides and Silica Coated Metal Oxides}

One type of commercial magnetic carrier originated from the work of Whitehead et al. [28]. Their preparation is based on the formation of silane polymers by condensation of 3-aminopropyltrimethoxysilane on the surface of magnetite particles. The silane polymers associate with the metal oxide either by forming a covalent bond with surface hydroxy groups through dehydration, or by adsorption of silane polymers onto the metal oxides. The resulting magnetic particles can be further functionalized to amine or carboxylic acid terminated carriers. The same method has been applied to the silanation of maghemite particles by Liu, who prepared a stable magnetic carrier by silane condensation on silica coated maghemite particles [26]. It has been shown recently that the surface coating on magnetic partcile by direct silanation is unstable, experiencing significant degradation in a base environment [27].

\section{Other Techniques}

In his review on magnetic coating and magnetic carrier technologies, Parsonage reports magnetic oil and chemical coating applications [5]. The principle of magnetic oil is that oil droplets will readily attach to, or spread over, the surfaces of particles that have been made hydrophobic or oleophilic. If the oil contains a finely dispersed magnetic phase, then a magnetic coating is formed. The so-called chemical coating methods consist in the conversion of the surface layer of a non-magnetic or weakly magnetic mineral to a more magnetic phase. These methods include roasting, oxidative alkaline pressure leaching, or surface decomposition of a gas phase [5].

\section{Process Development and Industrial Applications}

Results from Kolarik [19] on the Sirofloc ${ }^{\mathrm{TM}}$ process (see section on the Sirofloc ${ }^{\mathrm{TM}}$ process) were followed up by studies on process development 


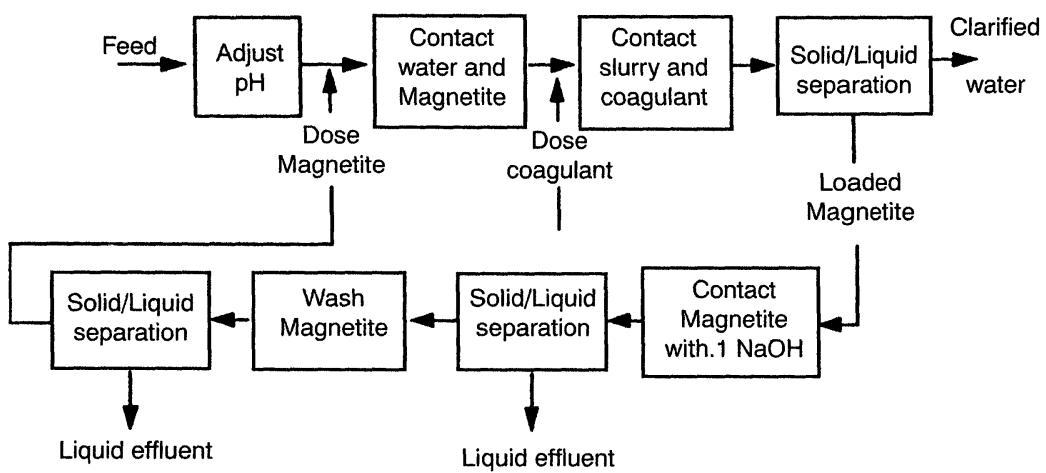

FIGURE 3 Process block diagram for color and turbidity removal with reusable magnetite particles (reprinted from Water Research, Vol. 17, Anderson and Priestley, Colour and turbidity removal with reusable magnetite particles - V, p. 1228, Copyright 1983, with permission from Elsevier Science).

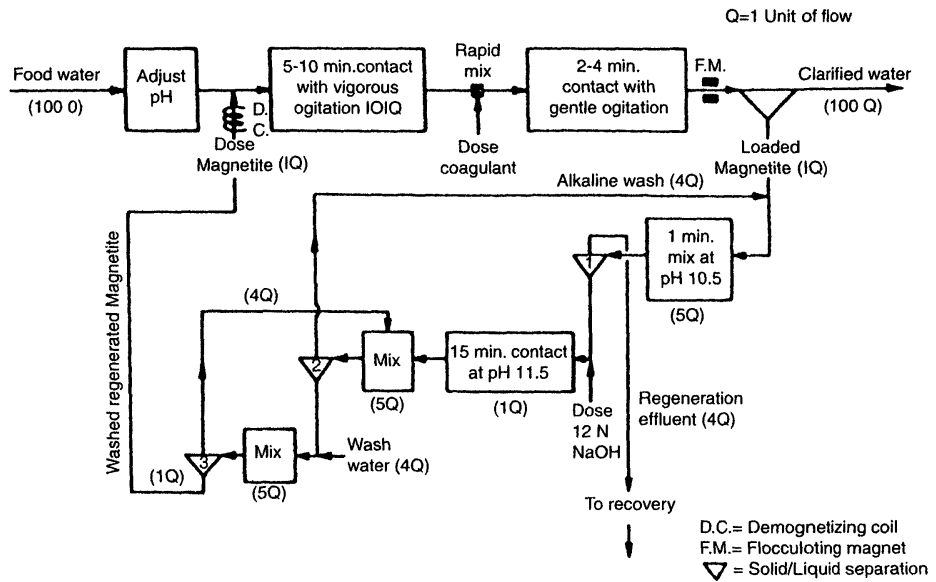

FIGURE 4 Process flow diagram (reprinted from Water Research, Vol. 17, Anderson and Priestley, Colour and turbidity removal with reusable magnetite particles - V, p. 1231, Copyright 1983, with permission from Elsevier Science).

and pilot plant operation $[29,30]$. The process development study showed that magnetite had to be demagnetized before contact with the water, in order to be fully dispersed and to present its 'full' surface area [29]. Figure 3 shows the process block diagram proposed by Anderson and Priestley, Figure 4 shows the corresponding process flow diagram, 


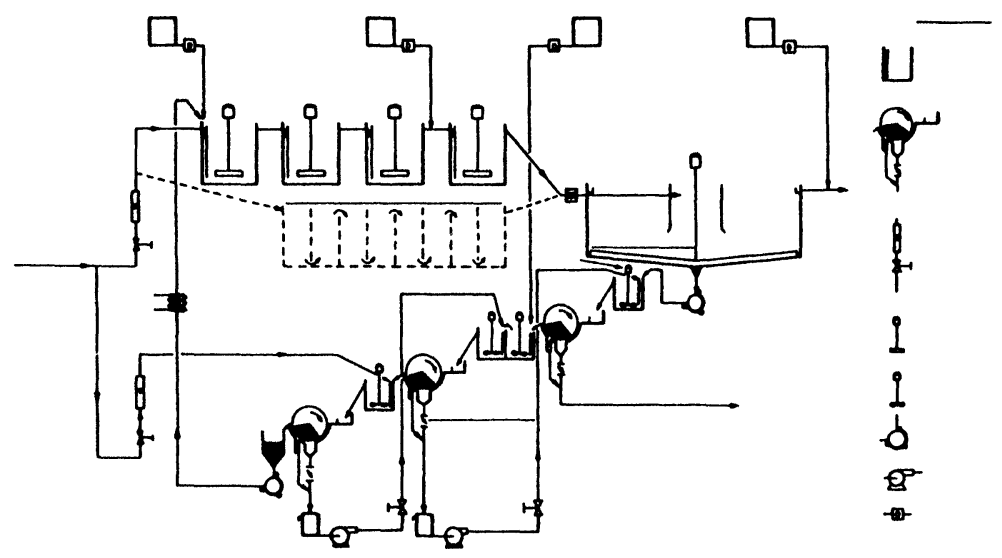

FIGURE 5 Pilot plant flowsheet and equipment specification (reprinted from Water Research, Vol. 17, Anderson and Priestley, Colour and turbidity removal with reusable magnetite particles - V, p. 1232, Copyright 1983, with permission from Elsevier Science).

and Figure 5 is a schematic representation of the pilot plant flowsheet with the equipment specifications (from [29]).

The patented Sirofloc ${ }^{\mathrm{TM}}$ process has been successfully demonstrated on a $0.2 \mathrm{ml}$ per day pilot plant at Malabar sewage treatment plant, Australia, and has been successfully scaled-up to $5 \mathrm{ml}$ per day [31]. The plant in Malabar was efficient in removing floating, suspended, and colloidal solids, as well as oil, grease, color, phosphates, and coliforms.

The first Sirofloc ${ }^{\mathrm{TM}}$ application outside Australia was commissioned in 1988 by Yorkshire Water at Redmires, England. Pilot plant studies and process development were carried out at Morehall Water Treatment Works, Yorkshire, on a $0.45 \mathrm{ml}$ per day scale [32]. It was demonstrated that the process can produce water which complies with EC Drinking Water Directive. Another study analyzed the first four months of operation at the full-scale $20 \mathrm{ml}$ day Redmires water treatment plant and showed that highly colored waters were efficiently treated [33]. The unit cost for potable water was lower or at least equivalent to that of other modern treatment works. The process avoided the use of primary coagulants and eliminated the problems associated with the carry-over of residual coagulant. Finally, the process enhanced the robustness of the plant in adapting to major changes in raw water quality. 


\section{Summary of Design Principles and Way Ahead}

From this review, some key characteristics for the design and preparation of magnetic carriers can be outlined. The following address the issues of removal (or adsorption) capacity, selectivity, robustness (or potential for prolonged reuse), process parameters, and costs.

\section{Selectivity}

Two principal ways by which selectivity is achieved are electrostatic adsorption and functionalization. For magnetite based carriers, electrostatic adsorption is the main interaction mechanism affecting selectivity. Electrostatic adsorption occurs either by hetero-coagulation of species of opposite surface charge or by double layer compression. Selectivity can be monitored by controlling the zeta-potential of the species, and is usually achieved by adjusting $\mathrm{pH}$, ionic strength, or by surfactant addition. It was established that the amphoteric character of iron oxide species allows the reversible adsorption and desorption of target species by setting the $\mathrm{pH}$ below or above the pzc. Functionalization relates to specific coupling mechanisms between the surface species of the carrier and the surface species of the target. Highly selective carriers can be designed this way, based on the key-lock principle. The selectivity in this case depends primarily on the ability to prepare functionalized particles. Surfactant coated magnetic particles and graft polymerized magnetic polymer beads were developed for this purpose.

\section{Removal Capacity}

Removal, or adsorption capacity depends mainly on the available reactive surface area, or the surface binding site density of the magnetic carriers. Particle size is crucial with respect to reactive surface area. For example: $16 \mu \mathrm{m}$ particles have a surface area of $2 \mathrm{~m}^{2} / \mathrm{g}$ while $30 \mathrm{~nm}$ sized particles have a surface area of $40-50 \mathrm{~m}^{2} / \mathrm{g}$. In the case of functionalized carriers, the corresponding parameter would be functional group density. Another key point is to maintain the colloid in a dispersed form, to present maximum available surface area. Therefore, the colloidal stability of the carrier suspension is a factor to monitor. The parameters affecting colloidal stability are mainly surfactant addition, and $\mathrm{pH}$. 


\section{Robustness}

Some problems seem to arise with "composite" carriers (e.g., gel-coated or functionalized) upon prolonged use. The two issues at stake are: coating deterioration, and irreversible adsorption of the species. The first issue relates to the robustness of coatings: i.e., the resistance to acid and base attack during regeneration, as well as the resistance to shear and other mechanical shocks during use must be assessed. Composite materials are obviously the ones prone to these kinds of problems. The other problem is associated with desorption of adsorbed species: how reversible is the adsorption of the species to be removed? No problems occurred with bare magnetite particles, but some arose with magnetic polymer beads and gel coated magnetite. A related issue is the kinetics of desorption, which should also be assessed.

\section{Process Parameters}

One of the principal advantages of magnetic carrier technology is that it can be easily used industrially. Magnetic carriers allow for truly continuous processes. They can be used in fluidized beds. Appropriately designed magnetic carriers can allow fast reaction rates, high separation efficiency, and selective separation. One of the key parameters in the adsorption processes is the stirring speed. This has to be optimized so to allow high contacting rates while avoiding excessive shear. Some other parameters related to the dispersion of the colloid, include demagnetization and $\mathrm{pH}$ control.

\section{Cost Considerations}

Some full-scale applications have shown that a careful design of a magnetic carrier based process can be economical. Some of the costs incurred for materials such as magnetic carriers and reagents can be offset by the improved process efficiency and by the reuse of the carriers and the recycling of the separated species.

\section{The Way Ahead}

Many challenges remain, in particular in the area of composite magnetic carriers. There are two main issues: First, to "graft" appropriate function groups on a magnetic core while leaving the function group "free" for 
further reaction; second, to provide a stable, robust composite that will not degrade upon regeneration and reuse. A third issue is to maximize the density of function groups to increase adsorption capacity.

The only large-scale application so far is of the Sirofloc ${ }^{\mathrm{TM}}$ process, where magnetite is used as an indifferent adsorbent to remove various kinds of contaminants in municipal waters. There is a need to develop magnetic carriers that combine the robustness, ease of use, and potential for industrial application of bare magnetite with the specificity (or selectivity) of polymer grafted resins.

\section{CONCLUDING REMARKS}

Magnetic carrier principles and some of the technologies developed to date have been described. It was demonstrated that magnetic carriers can provide an innovative and efficient way to apply magnetic separation to non-magnetic species. The advantages over conventional methods for metal ion removal (e.g., precipitation and ion exchange) have been outlined. Magnetic carriers have been designed and developed to combine the advantages of adsorption technologies (such as ion exchange resins or activated carbon), namely removal to very low concentrations, specific adsorption of target species and fast reaction rates, with the advantages of magnetic separation, namely high separation efficiency and fast, continuous processing.

A wide variety of processes have been presented, ranging from the unselective, large scale Sirofloc ${ }^{\mathrm{TM}}$ process, to the very specific laboratory scale affinity separation carriers used in biological cell separation. Two main kinds of carriers have been developed, bare carriers where adsorption occurs directly on the surface of the magnetic material and is controlled primarily electrostatically, and composite carriers where adsorption is controlled by the properties of a material bound to the magnetic particles. Composite carriers were developed for two purposes: (i) to increase the loading capacity of the carrier (e.g., gel-coated magnetite), and (ii) to increase the selectivity of the carrier by tailoring the functional group responsible for adsorption (e.g., whisker-type resins). For selective recovery of metal ions from effluents generated by the metallurgical industry, there is still the need to develop inexpensive magnetic carriers that would combine high loading capacity, robustness, and selectivity. 


\section{References}

[1] Urbain, O.M. and Steman, W.R. "Magnetic flocculation for removing suspended matter from whey, distillery and east plant wastes, straw board-mill wastes etc.," $U S$ Patent 2,232,294 (February 18, 1941).

[2] Moffat, G., Williams, R.A., Webb, C. and Stirling, R. "Selective separation in environmental and industrial processes using magnetic carrier technology," Minerals Engineering, 7(8), 1994, 1039-1056.

[3] Dixon, D.R. "Magnetic adsorbents: Properties and applications," J. Chem. Tech. Biotechnol., 30, 1980, 572-578.

[4] Chen, W.Y., Anderson, P.R. and Holsen, T.M. "Recovery and recycle of metals from wastewater from a magnetite-based adsorption process," Research Journal WPCF, 63(7), 1991, 958-964.

[5] Parsonage, P. "Coating and carrier methods for enhancing magnetic and flotation methods," in Colloid Chemistry in Mineral Processing, J.S. Laskowski and J. Ralston eds., Elsevier, Amsterdam, 1992.

[6] Ugelstad, J., Ellingsen, T., Berge, A. and Helgee, B. Patent WO 83103920, 1993.

[7] de Latour, C. "Seeding principles of high gradient magnetic separation," Journal of American Water Works Association, 68, August 1976, 443-446.

[8] Parsonage, P. "Selective magnetic coating for mineral separation," Trans. Inst. Min. Metall, (Sect. C: Mineral Process. Extr. Metal.), 93, March 1984, C37-C44.

[9] Terashima, Y., Ozaki, H. and Sekine, M. "Removal of dissolved heavy metals by chemical coagulation, magnetic seeding and high gradient magnetic separation magnetic filtration," Wat. Res., 20(5), 1986, 537-545.

[10] Anderson, N.J., Bolto, B.A., Elderidge, R.J., Kolarik, L.O. and Swinton, E.A. "Colour and turbidity removal with reusable magnetic particles-III. Immobilized metal hydroxide gels," Wat. Res., 16, 1982, 1327-1334.

[11] Benjamin, M.M., Hayes, K.F. and Leckie, J.O. "Removal of toxic metals from powergeneration waste streams by adsorption and co-precipitation," Journal WPCF, 54(11), November 1982, 1472-1481.

[12] Bolto, B.A., Dixon, D.R., Swinton, E.A. and Weiss, D.E. "Continuous ion exchange using magnetic shell resins. I. Dealkalization - Laboratory scale," J. Chem. Tech. Biotechnol., 29, 1979, 325-331.

[13] Bolto, B.A. "Novel water treatment processes which utilize polymers," J. Macromol. Sci. Chem. A, 14(1), 1980, 107-120.

[14] Anderson, N.J., Dixon, D.R. and Swinton, E.A. "Continuous ion exchange using magnetic shell resins. II. Dealkalization - Pilot plant study," J. Chem. Tech. Biotechnol., 29, 1979, 325-331.

[15] Bolto, B.A., Dixon, D.R. and Elderidge, R.J. "Graft polymerization on magnetic polymer substrates," J. Appl. Poly. Sci., 22, 1978, 1977-1982.

[16] Anderson, N.J., Kolarik, L.O., Swinton, E.A. and Weiss, D. "Colour and turbidity removal with reusable magnetic particles-II. Coagulation with magnetic polymer composites," Wat. Res., 14, 1980, 967-973.

[17] Furosawa, K., Nagashima, K. and Anzai, C. Colloid. Polym. Sci., 272, 1994, 1104.

[18] Butterworth, M.D., Bell, S.A., Armes, S.P. and Simpson, W. J. Colloid. Interface Science, 183, 1996, 91-99.

[19] Kolarik, L.O. "Colour and turbidity removal with reusable magnetite particles-IV. Alkali activated magnetite - A new solid, reusable coagulant-adsorbent," Wat. Res., 17, 1983, 141-147.

[20] Anderson, N.J., Blesing, N.V., Bolto, B.A. and Jackson, M.B. "The role of polyelectrolytes in a magnetic process for water clarification," Reactive Polymers, 7, 1987, $47-55$.

[21] Anderson, N.J., Bolto, B.A., Elderidge, R.J. and Jackson, M.B. "Polyampholytes for water treatment with magnetic particles," Reactive Polymers, 19, 1993, 87-95. 
[22] Hwang, J.Y. US Patent 4,834,898, 1989.

[23] Hwang, J.Y. US Patent 4,906,382, 1990.

[24] Liu, Q. and Xu, Z. "Self-assembled monolayer coating on nanosized magnetic particles using 16-mercaptohexadecanoic acid," Langmuir, 11(12), 1995.

[25] Lin, Q. and $\mathrm{Xu}, \mathrm{Z}$. "Functionalization and applications of nanosized $\gamma-\mathrm{Fe}_{2} \mathrm{O}_{3}$ particles," J. Appl. Phys., 79(8), April 1996, 4702-4704.

[26] Lin, Q. "An innovative approach in magnetic carrier technology," Ph.D. Thesis, McGill University, Mining and Metallurgical Engineering Department, August 1996.

[27] Xu, Z., Lin, Q. and Finch, J.A. "Silanation and stability of 3-aminopropyl triethoxy silane on nanosized superparamagnetic particles: I. Direct silanation." Applied Surface Science, 120, 1997, 269-278.

[28] Whitehead, R.A. et al. US Patent 4,695,393, 1987.

[29] Anderson, N.J. and Priestley, A.J. "Colour and turbidity removal with reusable magnetite particles-V. Process development," Wat. Res., 17(10), 1983, 1227-1233.

[30] Anderson, N.J., Bolto, B.A., Blesing, N.V., Kolarik, L.O., Priestley, A.J. and Raper, W.G.C. "Colour and turbidity removal with reusable magnetite particles-VI. Pilot plant operation," Wat. Res., 17(10), 1983, 1235-1243.

[31] Booker, N.A. and Brooks, R.B. "Scale-up of the rapid sewage treatment Sirofloc process," Process Safety and Environmental Protection (Transactions of The Institution of Chemical Engineers Part B), 72, Part B, May 1994, 109-112.

[32] Gregory, R., Maloney, R.J. and Stockley, M. "Water treatment using magnetite: A study of a Sirofloc pilot plant," Journal of the Institution of Water and Environmental Management, 2, 1988, October, 532-544.

[33] Home, G.P., Stockley, M. and Shaw, G. "The Sirofloc process at Redmires watertreatment works," Journal of the Institution of Water and Environmental Management, 6, 1992, February, 10-18.

\section{BIOGRAPHY}

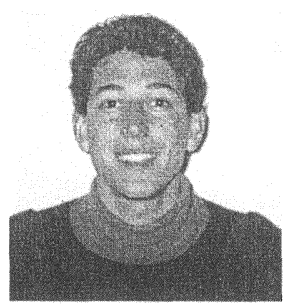

Joachim Broomberg was born in 1972 and graduated from the Faculty of Engineering at Ecole des Mines de St-Etienne, France, in 1995. He obtained a M. Eng. degree in Mining and Metallurgical Engineering from McGill University, Canada, in 1998.

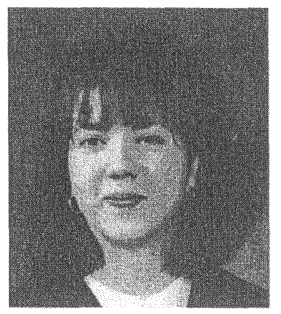

Stéphanie Gélinas was born in 1970. She obtained both B. Eng. (1993) and M.Eng. (1995) degrees in Chemical Engineering at McGill University, Canada. She is currently a Ph.D. candidate in the department of Mining and Metallurgical Engineering at McGill University, involved in the preparation of magnetic carriers through functionalization of nanosized maghemite particles. 


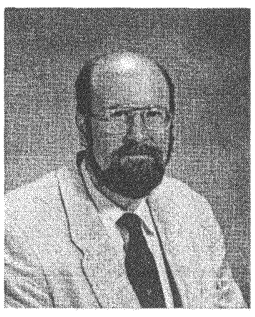

James A. Finch graduated from Birmingham University (Minerals Engineering), B.Sc. in 1969 and from McGill University (Metallurgical Eng.), M.Sc, 1971 and Ph.D., 1973. He has been on staff in the Department of Mining and Metallurgical Engineering, McGill University since 1973, becoming a full professor in 1985 and serving as Chair from 1988 to 1991. Since 1991 he has held successively the INCO-NSERC Chair (1991-1996) and Industry Chair in Mineral Processing (1996-). He has published over 150 articles and one book, Column Flotation, with Glenn Dobby. He holds the Gaudin Award (1997) SME/AIME, the Alcan Award (1996) MetSoc/CIM and Best Presentation Award (1995) CMP/CIM. 